\title{
AS NOVAS NÚPCIAS DA QUALIFICAÇÃO NO ALENTEJO
}

\author{
Bravo Nico ${ }^{1}$ \\ Lurdes Nico ${ }^{2}$ \\ Fátima Rute Ferreira ${ }^{3}$
}

\section{Introdução}

A presente comunicação insere-se na linha de investigação “Educação e Território", no âmbito do CIEP (Centro de Investigação em Educação e Psicologia) da Universidade de Évora. Pretende-se abordar três pontos fundamentais: (i) caracterização da rede regional actual do sistema de Reconhecimento, Validação e Certificação de Competências no Alentejo, comummente conhecido por RVCC; (ii) referência a alguns estudos efectuados no âmbito dos impactos do processo de RVCC na região Alentejo e em Portugal; (iii) apresentação do projecto de investigação, em curso, no âmbito da temática dos eventuais impactos do reconhecimento e validação dos adquiridos experienciais, na região Alentejo, no período 2001-2005, e qual a sua relação com o princípio da Aprendizagem ao Longo da Vida (ALV). Estes três pontos estão estruturados em seis tópicos:

1. Roteiro conceptual

2. O Aparecimento do Sistema de Reconhecimento, Validação e Certificação de Competências no Alentejo

3. Caracterização do Sistema de Reconhecimento, Validação e Certificação de Competências no Alentejo

4. O Funcionamento de um Centro Novas Oportunidades

5. Estudos efectuados no âmbito dos impactos do processo de RVCC

6. Apresentação do projecto de investigação “As Novas Núpcias da Qualificação no Alentejo"

\footnotetext{
${ }^{1}$ Departamento de Pedagogia e Educação da Universidade de Évora.

${ }^{2}$ Direcção Regional de Educação do Alentejo.

${ }^{3}$ Centro de Investigação em Educação e Psicologia da Universidade de Évora.
} 


\section{Roteiro Conceptual}

Em 2000, a Comissão Europeia, no "Memorando da Aprendizagem ao Longo da Vida”, apela à necessidade de se assegurarem "as novas competências básicas para todos ", para além daquelas que todos conhecemos como "ler, escrever e contar", promovendo a aquisição e/ou actualização das competências necessárias à participação e desenvolvimento de cada um(a) na sociedade. A aprendizagem adquirida, em diferentes ambientes, surge como uma mais valia, reconhecendo-se que se pode aprender em diferentes contextos, valorizando-se, pela primeira vez, numa perspectiva de certificar as aprendizagens realizadas em contextos não formais e informais (Comissão Europeia: 2000).

Procuremos, então, caracterizar cada um dos contextos de aprendizagem.

\section{A aprendizagem formal}

A aprendizagem dos indivíduos realiza-se para além da escola, enquanto estrutura formal que promove aprendizagens formais. Como refere António Firmino da Costa (2002a:10), “na sociedade educativa contemporânea, está em pleno desenvolvimento a multi-aprendizagem".

Cavaco (2002) refere que a aprendizagem formal é aquela que é veiculada pelas escolas, com programas, horários pré-definidos e processos de avaliação. Os ambientes em que este tipo de aprendizagens ocorre são organizados e comportam intencionalidade educativa e certificação oficial (Amorim, 2006:34).

Para Canário (1999, cit. por Cavaco 2002:29), a aprendizagem formal é, indiscutivelmente, um meio importante para o desenvolvimento dos indivíduos, mas não é singular. Ela decorre em instituições de ensino e formação e conduz a diplomas e qualificações reconhecidos e onde se verifica uma "estruturação prévia de programas e horários, na existência de processos avaliativos e de certificação”.

\section{A aprendizagem não formal}

Quanto à aprendizagem proporcionada nos contextos onde a educação é não formal, esta é, para Correia \& Cabete (2002:45-46), “ a única forma de aprendizagem da maioria dos adultos". Norbeck (1979, cit. por Nogueira, 1996:42) considera que 
cabe aos sujeitos interessados procurarem actividades que promovam este tipo de aprendizagem, sendo competência do Estado apoiar e proporcionar a oferta de oportunidades nesse âmbito.

Há outros autores, como Canário (1999, cit. por Cavaco, 2002:29), que consideram a aprendizagem não formal como aquela em que há flexibilidade de programas e horários, é baseada no voluntariado e é característica na área da Educação de Adultos.

A UNESCO (1988, cit. por Nogueira, 1996:42) entende a aprendizagem não formal como não organizada "por cursos e graus escolares regulamentados" e, ao invés da aprendizagem formal, não concede títulos ou certificados e pode decorrer em espaços como museus, teatros ou associações (Correia, 2006:268).

\section{A aprendizagem informal}

A aprendizagem informal é uma aprendizagem não organizada, que pode ser intencional ou não. A expressão educação informal teve a sua génese na Conferência de Williamsburg, num relatório elaborado por Schwartz, em 1969 (Cavaco, 2002).

Para Canário (1999), as aprendizagens informais constituem "situações potencialmente educativas, mesmo que não conscientes, nem intencionais (...) correspondendo a situações pouco estruturadas e organizadas”. Já Coombs (cit. por Cavaco, 2002:29) salienta que a aprendizagem informal ocorre ao longo da vida, adquirindo-se conhecimentos, capacidades e saberes mediante a multiplicidade de experiências e vivências. Nos contextos em que se desenvolvem aprendizagens informais, "não há reconhecimento social de quem exerce a função educativa" (Cavaco, 2002:36). Também Amorim (2006: 34) e Nico B. \& Nico, L. et al (2008a:211) afirmam que se constituem como aprendizagens não intencionais realizadas no quotidiano, muitas vezes caracterizadas pelo fraco reconhecimento individual (pelo próprio) e socialmente.

A aprendizagem experiencial é um conceito que surge, com alguma frequência, associado à aprendizagem informal. Constituindo este tipo de aprendizagem uma das mais importantes, para grande parte dos adultos que se inscreveram nos Centros RVCC, e sendo este o nosso objecto de estudo, consideramos importante caracterizar o conceito. 
Carneiro (2001), a propósito deste tipo de aprendizagem, reafirma que todos os adultos têm experiências nas quais aprendem, sobretudo se desprendidos de certas "obrigações" e ou condicionalismos a que a vida, tantas vezes, conduz. É o carácter de inconsciência que parece marcar esta categoria de aprendizagem, na medida em que, amiúde, nem nos damos conta que estamos, efectivamente, a aprender.

Há, ainda, quem utilize o conceito de aprendizagem contextual, como Quintas (2008:31), quando este afirma que “a aprendizagem não resulta só de um processo pessoal, isolado do mundo em que o sujeito vive, mas está intimamente relacionada com esse mundo e é afectada por ele."

A Comissão Europeia veio dar um impulso muito forte à aprendizagem experiencial e aos contextos em que ocorre, confirmado, por exemplo, no elevado número de recomendações, relatórios e conferências à escala europeia.

\section{O conceito competência}

Sendo inquestionável, na literatura, a existência de diversos ambientes de aprendizagem, o mesmo já não se poderá dizer do conceito de competência. Vários autores tratam a temática, destacando-se como "a faculdade de mobilizar um conjunto de recursos cognitivos (saberes, capacidades, informações, etc) para solucionar com pertinência e eficácia uma série de situações." (Perrenoud:2000), não especificando o contexto em que a mesma é construída/reforçada.

No processo de RVCC (Reconhecimento, Validação e Certificação de Competências), que é o objecto de reflexão nesta comunicação, o conceito de competência assume um papel importante, pois trata-se de reconhecer, formalmente, as competências que o adulto adquiriu ao longo da sua experiência de vida, valorizando este e a respectiva relação que estabeleceu com o contexto em que vive.

A figura seguinte procura identificar as 6 características que, na nossa perspectiva, surgem associadas ao conceito de competência. 


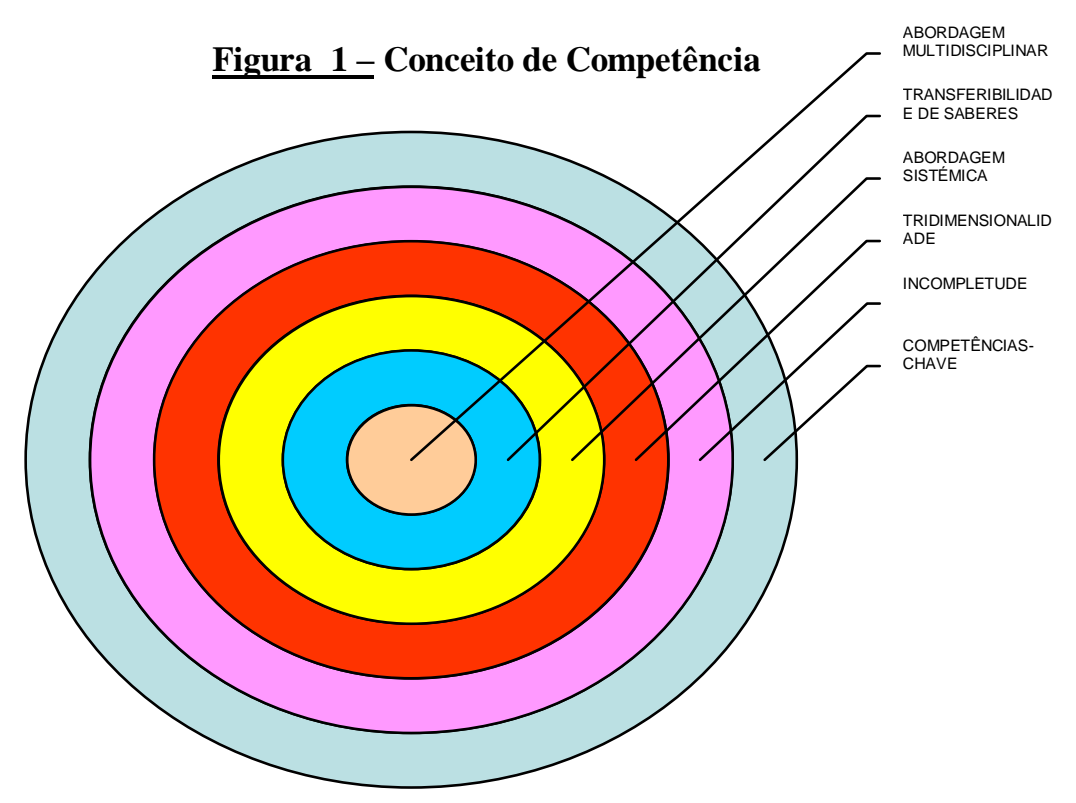

\section{A Abordagem Multidisciplinar/Polissemia}

São vários os autores que se centram nesta temática, pelo que apresentamos aqui algumas das definições que melhor respondem àquilo que é o nosso entendimento sobre competência. Roldão (2003:15-16) chega mesmo a afirmar que estamos perante um fenómeno de "bombardeamento", tal são as diferentes proveniências e referências ao conceito. Sermos mais competentes, é na sua opinião “...sermos capazes de usar adequadamente os conhecimentos..." nas diferentes áreas do saber e das esferas da vida.

São diversas as áreas disciplinares que têm vindo a desenvolver trabalho de análise e compreensão deste conceito. Segundo Aubret et al (1993:19-20, cit. por Pires, 2005:263) as diferentes abordagens têm contribuído para três níveis de análise: o nível individual (Psicologia, Ciências da Educação); o nível do grupo/sociedade (Sociologia, Psicologia Social) e o nível empresarial (Direito, Economia, Gestão.). Esta abordagem multidisciplinar é desenvolvida por Pires (2005).

$\mathrm{Na}$ área das Ciências da Educação, há várias definições do conceito de competência. Apresentamos aquela que nos é referida no Dicionário de Pedagogia, segundo a qual "ter uma competência é possuir um saber ou uma habilidade de uma qualidade reconhecida, num domínio definido; ser competente tem o mesmo sentido, é 
fazer prova de saber e, no limite, ser um perito no domínio considerado." (Arénilla et al, 2001:105).

A competência, enquanto "conceito polissémico, abrangendo conhecimentos, capacidades, dimensões metacognitivas e simbólicas que se mobilizam permanentemente na acção", tem vindo a ser analisado a partir de "diferentes campos disciplinares, traduzindo uma grande diversidade de abordagens" (Correia \& Cabete, 2002b:44).

\section{A Transferibilidade e mobilidade de saberes}

Phillipe Perrenoud e Le Boterf são dois dos principais teóricos a defender a organização do trabalho educativo por competências.

A transferibilidade e a mobilidade de saberes também caracterizam o conceito de competência, pois esta constrói-se sempre na ligação a um contexto, podendo, depois, ser transferido esse mesmo saber e conhecimento para outras situações. A este propósito, importa referir que nos modelos britânico e francês, este conceito integra esta capacidade de aplicarmos o que sabemos (conhecimentos, habilidades, capacidades), o saber-fazer e também o saber-ser mobilizados para dar resposta aos problemas e situações diárias (Santos \& Fidalgo, 2007:83-85; Ministério da Educação, 1998:18). A aplicação/utilização daquilo que sabemos é sinónimo de que se "deu a passagem” para a competência, a qual se realiza na acção, como refere Le Boterf (1994:16, cit. por Alves et al:2006:270).

O desempenho competente de um indivíduo alimenta-se da capacidade para agir nas situações, mobilizando um conjunto de recursos (capacidades, conhecimentos, saberes, atitudes, valores) adquiridos num determinado contexto mas depois colocados ao serviço de diferentes tarefas, solicitações e contextos (Le Boterf, 1994, 2001; Perrenoud, 1997 in Rodrigues \& Peralta, 2006:233; Gomes et al, 2006:33; Rens, 2001:55; Ávila, 2008:95). Esta transferibilidade do conceito de competência, além da ligação à acção/contexto, é constituída por diversos saberes: "saberes formalizados, saberes práticos, saber-fazer, saber relacional, saber cognitivo e saber emocional" (Gonçalves \& Fernandes, 2007:14).

Perrenoud (2000:19-31) assume competência como "a faculdade de mobilizar um conjunto de recursos cognitivos (...) para solucionar com pertinência e eficácia 
uma série de situações." Ela é "um saber em uso" (Perrenoud, 1995, cit. por Roldão, 2003:20), isto é, uma capacidade efectiva que os indivíduos têm para, nas diferentes situações, utilizarem esse saber, não se tratando de conteúdos teóricos que, sob o ponto de vista prático nada valem, mas que são traduzíveis em acções concretas. Roldão (2003:20), recorrendo à metáfora de Lévy-Strauss “utensílios do pensamento” e no sentido de competência aqui referido, considera que se pode estabelecer uma ligação entre aquela metáfora e a noção de saber e conhecimento, que a noção de competência incorpora e que também se encontra na análise e pensamento de Guy Le Boterf.

\section{A Abordagem sistémica}

A complexidade e a ligação ao contexto descrito, conduzem-nos a uma abordagem sistémica do conceito de competência, tal como preconiza Pires (2005), segundo a qual há um carácter dinâmico e valorizador do que o adulto traz e adquiriu nos diversos contextos vitais (Gomes, 2006:16; Amorim, 2006:34). As competências "são entendidas numa perspectiva sistémica, como a mobilização em acto de saberes, capacidades e recursos, (...) construídos e integrados em situações de aprendizagem explícita ou implícita, em contextos diversificados de experiência pessoal, profissional, social, ou seja de vida." (DGFV, 2004). Na abordagem humanista da Psicologia valoriza-se o processo de aprendizagem como um todo "global, integrador, e holístico" sendo, por isso, uma das influências mais presentes nesta abordagem sistémica que é referenciada na análise e definição do conceito de competência (Pires, 2005:272).

Há dois pólos que surgem associados e interligados no conceito de competência, resultando daí o seu carácter sistémico. Na realidade, o indivíduo e o meio constituemse como uma "unidade funcional e bipolar" (Le Boterf, 1994, 1997, cit. por Pires, 2005:291) e tudo aquilo que é apreendido, assimilado e aprendido, ainda que de forma diferente por cada um, realiza-se no contexto de uma determinada situação, por isso " $o$ sujeito é sempre um sujeito situado" (Pires, 2005: 291).

O modelo dinâmico de competência referido assenta no facto desta se realizar na acção e em situações concretas sendo, enquanto tal, uma capacidade para agir e reagir a determinadas situações, mobilizando, para isso, os saberes, conhecimentos, capacidades e atitudes que o indivíduo possui.

Esta característica, com a qual concordamos, contribui para a afirmação de uma orientação mais construtivista e menos tecnicista da aprendizagem e da formação dos 
indivíduos, respeitando o ponto de partida de cada um e centrando-se no indivíduo aprendente, ou seja, aquilo que ele adquiriu nos diferentes contextos de vida (Alonso, 2000:21; Howard, 2001:98).

\section{A Tridimensionalidade}

Competência é um conceito que integra diferentes dimensões. Este aspecto está relacionado com a abordagem sistémica, assente na importância da mobilização de diversos saberes: saber (conhecimentos), saber-fazer (capacidades) e saber-ser (atitudes), traduzidos num saber em acção integrado (Alonso et al, 2001:97). Os primeiros saberes também são designados de "teóricos" e adquirem-se, essencialmente, através dos espaços formais de aprendizagem, "são objecto de formalização, o que permite a sua transmissão e aquisição"; os segundos estão relacionados com os saberes procedimentais/operativos e "podem resultar de um processo de operacionalização dos saberes teóricos, mas o treino é necessário para a sua aquisição”; os terceiros decorrem das atitudes e do quadro de valores que lhe está subjacente e que Le Boterf identifica enquanto "saberes-fazer relacionais" adquiridos através da socialização que ocorre nos diversos contextos pessoais e laborais (Pires, 2005: 299-301).

A competência, por estar sempre associada a um contexto, é conotada, por isso, a processos experienciais, a um "saber tácito", um saber em acção ou em uso, que "não se ensinam e não são passíveis de explicação" (Kuenzer, 2002:1. cit. por Fidalgo \& Fidalgo, 2007:36; Boavida \& Barreira, 2004:782). “As competências são o accionar/activar - a acção efectiva - dos saberes." (Lages, 2006:474). Esta opinião é também corroborada por Ávila (2008:93) quando esta refere que, sendo a competência inseparável da acção, remetem "antes de mais, para a acção dos indivíduos num determinado contexto". Le Boterf remete também para esta dimensão ao afirmar que a competência “realiza-se na acção” (cit. por Ávila, 2008:93).

A propósito dos processos experienciais, já tivemos oportunidade de aprofundar a importância das aprendizagens informais e experienciais.

Foi com a ANEFA que, em Portugal, se começou a valorizar - através da criação do dispositivo de RVCC - aquilo que os indivíduos fazem, no quotidiano, o que sabem e aplicam em situações reais. Remetem-nos, alguns autores, para as "competências em uso social e efectivo”, e não apenas as qualificações formais (lógica dos diplomas), 
como até aí vigorou (Costa, 2002:183). Constitui-se e valoriza-se como "um saber-agir socialmente reconhecido, que assenta num processo combinatório de mobilização de recursos" (Rico, 2007:46), traduzido por "um sistema de conhecimentos, conceptuais e processuais” (Pinto, 2006:337; Gomes, 2006:12). A este propósito, Perrenoud (2000) descreve o "conjunto de recursos cognitivos" como "saberes, capacidades, informações, etc.." (Rico, 2007:46).

A competência, assim definida, é entendida como uma espécie de "top-model" no campo da formação, em substituição da anteriormente designada qualificação (Alves et al, 2006:256).

\section{A “Incompletude"}

Todos os indivíduos são portadores de competências mas a sua formação e aquilo que vão aprendendo é sempre insuficiente e, desse modo, nunca é tido como um ciclo concluído mas em permanente construção, num processo em que "todos os sujeitos são incompletos do ponto de vista do seu processo de formação e desenvolvimento; e também têm competências incompletas quando confrontados com os padrões valorizáveis numa sociedade baseada no conhecimento” (Santos Silva., 2001b:58). Gilberto Velho ${ }^{4}$ defende que “ A pessoa é projecto”, no sentido de que todos são incompletos e, portanto, a formação tem de ter essa noção de incompletude.

Também num processo de reconhecimento e validação dos adquiridos, encontramos esta noção de incompletude, pois os técnicos que o acompanham estão, não apenas a identificar aquilo que o indivíduo adquiriu pela experiência de vida, mas também a identificar as incompletudes transformadas em potencialidades de aprendizagem e formação em fases subsequentes, como refere Santos Silva "competências incompletas às quais há sempre algo a acrescentar" (2001:58), ideia corroborada por Lages (2006:468).

\section{As Competências-Chave}

\footnotetext{
4 Antropólogo Brasileiro parafraseado por Ricardo Vieira, professor do Instituto Politécnico de Leiria, numa comunicação apresentada no III Seminário de Educação - Memórias, Histórias e Formação de Professores, promovido pelo Núcleo de Pesquisa e Extensão Vozes da Educação: Memória e História das Escolas de São Gonçalo e Núcleo de Extensão da Faculdade de Formação de Professores (NExt-FFP), nos dias 4 e 5 de Setembro de 2007, Rio de Janeiro, Brasil.
} 
Ao nível da Educação e Formação de Adultos, em percursos formativos como os Cursos EFA e nos processos de RVCC, as competências, entendidas como Competências-Chave, são traduzidas como um "conjunto (...) de representações, conhecimentos, capacidades, comportamentos, atitudes, enfim, de saberes (...) mobilizáveis e transferíveis na acção/reacção resolutiva de um problema concreto." (Amorim, 2006:35).

As competências-chave (qualificações-chave ou aptidões-chave) surgem sempre contextualizadas e nunca em "pacotes descontextualizados", constituindo-se como um complemento e não como um substituto das qualificações adquiridas nos espaços formais de aprendizagem, defendendo-se a existência de uma relação de continuidade entre competência e qualificação (Rens, 2001:51; Imaginário, 2007:9).

As competências básicas ou chave entendidas como "literacia linguística, numérica, tecnológica, científica, cultural e comportamental" são fundamentais na sociedade actual, constituindo-se como "novas competências básicas", para uma eficaz integração na sociedade global e do conhecimento. As competências básicas (novas ou as clássicas "ler, escrever e contar", como a elas se refere Silva et al, 2002: 31-34) são essenciais na promoção de uma aprendizagem ao longo da vida, estruturada e certificada. As competências-chave são, ainda, tidas enquanto construto e instrumento que serve de elo de ligação entre a educação, a formação e o desenvolvimento local (Trigo, 2001a:104).

Dominicé (1998) defende a construção das competências, enquanto processo dinâmico e articulado entre as aprendizagens formais e as experienciais, no decorrer da vida do sujeito, em que ambas se valorizam mutuamente num processo contínuo. É com base nesse articulado que podem residir as diferentes relações dos indivíduos com o saber e "o sentido que o adulto atribui ao seu percurso escolar influencia fortemente a sua relação com a aprendizagem presente e futura, e com os sistemas de formação, articulando-se indirectamente com a sua eficácia." (Dominicé, 1998, cit. por Pires, 2005:304-305).

2. O Aparecimento do Sistema de Reconhecimento, Validação e Certificação de Competências no Alentejo 


\section{Níveis de qualificação}

Em termos globais, a sociedade portuguesa encontra-se, ainda, com níveis de qualificação aquém daquilo que é a realidade de outros parceiros europeus.

Em Portugal, cerca de 3.500.000 dos actuais activos têm uma taxa de escolaridade inferior ao nível secundário; destes, 74\% têm uma escolarização inferior ao 9. ${ }^{\circ}$ ano de escolaridade. Por outro lado, cerca de 485.000 jovens, entre os 18 e os 24 anos (45\% no total), ingressaram no mercado de trabalho sem terem concluído o ensino secundário e mais de metade destes (266.000) não chegaram a concluir os 9 anos de escolaridade obrigatória (www.portugal.gov.pt/Iniciativa).

A par destes indicadores, um outro continua a marcar negativamente a sociedade portuguesa: cerca de 838.140 indivíduos não sabem ler nem escrever. No Alentejo, de acordo com o Instituto Nacional de Estatística (Recenseamento Geral da População, 2001), existe uma taxa de $17,1 \%$ de analfabetismo, sendo a escolarização traduzida no Quadro 1:

Quadro 1 - Níveis de Escolaridade no Alentejo

\begin{tabular}{|l|c|c|c|}
\hline \multirow{2}{*}{$\begin{array}{c}\text { Nivel de } \\
\text { Ensino atingido }\end{array}$} & \multirow{2}{*}{$\begin{array}{c}\text { Frequências } \\
\text { Absolutas }\end{array}$} & \multicolumn{2}{c|}{ Frequências Relativas (\%) } \\
\cline { 3 - 4 } & 111580 & Alentejo & Portugal \\
\hline Nenhum & 192576 & 20,9 & 14,2 \\
\hline $\mathbf{1}^{\mathbf{0}}$ Ciclo & 59642 & 11,1 & 35,2 \\
\hline $\mathbf{2}^{\mathbf{0}}$ Ciclo & 54412 & 10,1 & 12,6 \\
\hline $\mathbf{3}^{\text {o Ciclo }}$ & 73660 & 13,7 & 10,8 \\
\hline Secundário & 2552 & 0,5 & 15,7 \\
\hline Médio & 41324 & 7,7 & 0,8 \\
\hline Superior & $\mathbf{5 3 5 7 4 6}$ & $\mathbf{1 0 0 , 0}$ & 10,7 \\
\hline Totais & & 100,0 \\
\hline
\end{tabular}

Fonte: INE, Censos de 2001. 


\section{A origem da sigla $R V A E$}

A RVAE (Reconhecimento e Validação dos Adquiridos Experienciais), a partir das décadas de 80 e 90, na Europa, afirma-se cada vez mais como uma necessidade, por parte dos indivíduos que, ao longo da vida, foram adquirindo experiências e acumulando aprendizagens, a partir das vivências. O reconhecimento e validação dos adquiridos experienciais torna-se objecto de análise e reflexão no âmbito da problemática da aprendizagem ao longo da vida, discutida em sede de reuniões e conferências mundiais e europeias (Alcoforado, 2001:69; Ministério da Educação, 2007b:14). No contexto europeu, o RVAE aparece relacionado com a aprendizagem e formação ao longo da vida (Santos \& Fidalgo, 2007:82).

São vários os trabalhos desenvolvidos na área do RVAE, como os de: (i) Colardyn (1996) sobre os países do Grupo dos 67 e a Austrália; (ii) da OCDE sobre a Educação e Formação de Adultos; (iii) Estratégias de Aprendizagem ao Longo da Vida (ALV) esboçadas em Declarações (Declaração de Copenhaga e Declaração de Bolonha); (iv) o Inventário Europeu de abordagens de validação impulsionado pela Comissão Europeia e pelo CEDEFOP ${ }^{5}$ (em 1999); (v) Programas europeus (Erasmus, Sócrates, Equal, entre outros).

Em Portugal, destacamos os estudos de carácter institucional de organismos, entretanto extintos, como a Agência Nacional de Educação e Formação de Adultos (ANEFA) que introduziu o dispositivo de RVAE em Portugal - com a designação de RVCC - e também os trabalhos do INOFOR (Instituto para a Inovação na Formação) e da Direcção-Geral de Formação Vocacional/DGFV (Pires, 2006:440).

No âmbito da valorização/reconhecimento dos adquiridos experienciais, um dos momentos mais importantes decorreu da Conferência de Hamburgo, em 1997, entre outras iniciativas em países da União Europeia, de que Portugal é um exemplo (Alcoforado, 2001:69).

\footnotetext{
${ }^{5}$ CEDEFOP - Centro Europeu para o Desenvolvimento de Formação Profissional.
} 


\section{O papel da ANEFA na construção de um Sistema Nacional de RVCC}

Face aos baixos níveis de qualificação era necessário dar uma resposta de qualificação adequada à população adulta. Em 2001, foram criados, numa iniciativa da ANEFA (Agência Nacional para a Educação e Formação de Adultos, 1999-2002), os Centros de Reconhecimento, Validação e Certificação de Competências (CRVCC), nos quais se realizaram os primeiros processos de Reconhecimento, Validação e Certificação de Competências.

Entre 2001 e 2005, existiram, na região do Alentejo, 6 CRVCC, tutelados pela ANEFA, de acordo com a cronologia que se apresenta em seguida:

Cronograma do Sistema de Reconhecimento, Validação e Certificação de Competências no Alentejo (2001-2005)

2001 - A Esdime (Associação para o Desenvolvimento Local no Alentejo Sudoeste) foi uma das primeiras seis entidades, a nível nacional, a constituir-se como Centro de RVCC, em Ferreira do Alentejo.

2001 - Criação do CRVCC da Fundação Alentejo, em Évora.

2003- Criação do CRVCC da ADL (Associação para o Desenvolvimento do Litoral Alentejano), em Santiago do Cacém. *

2004 - Criação do CRVCC da Rota do Guadiana (Associação de Desenvolvimento Integrado), em Serpa.

2005 - Criação do CRVCC da Associação Terras de Dentro, em Alcáçovas (Viana do Alentejo).

*Centro que encerrou a actividade em 2005 e foi extinto em 2007 (Despacho n. ${ }^{\circ}$ 1073/2007, DR 15, Série II, de 22-01-2007).

Após 2005...

Considerando:

- o objectivo de melhorar os níveis de qualificação dos portugueses;

- a avaliação e monitorização feita aos primeiros CRVCC; 
- o facto de, em 2002, já ter sido reconhecida a necessidade de se definir uma estratégia que promovesse, a nível europeu, a aprendizagem ao longo da vida, numa forte aposta nos sistemas de educação e formação de cada país (“Educação e Formação 2010”);

surgiu, no ano de 2005, a Iniciativa Novas Oportunidades, assumida como um desafio de transformar e desenvolver os níveis de qualificação da população portuguesa, com dois objectivos fundamentais: os jovens (evitando que abandonem os estudos sem o nível secundário de educação) e os adultos (aumentar a qualificação de quem há vários anos ingressou no trabalho sem ter concluído ou aumentado a qualificação).

De um modo geral, esta Iniciativa procura criar oportunidades que permitam definir o $12 .^{\circ}$ ano como patamar mínimo de escolaridade.

\section{Caracterização do Sistema de Reconhecimento, Validação e Certificação de Competências no Alentejo}

No Alentejo, a Direcção Regional de Educação do Alentejo, no ano de 2005, desenvolveu estratégias de promoção do alargamento da Rede, de acordo com orientações da Direcção Geral de Formação Vocacional (DGFV, 2002-2006) que, então, tutelava, a nível nacional, a rede de Centros de RVCC existente.

No contexto da Iniciativa Novas Oportunidades já referida, os Centros RVCC passaram a assumir novas funções, enquanto locais de porta de entrada dos jovens e dos adultos para um percurso de formação e qualificação que melhor se adeqúe ao seu percurso de vida e perfil de competências evidenciado, passando a designar-se Centros Novas Oportunidades.

Em 2010, existe uma rede com 32 Centros (cf. quadro seguinte)

Quadro 2 - Rede de Centros Novas Oportunidades no Alentejo

\begin{tabular}{|l|c|c|}
\hline \multicolumn{2}{|c|}{ Centros Novas Oportunidades } & N. $^{{ }^{\mathbf{}}}$ \\
\hline Entidades Privadas & 9 \\
\hline \multirow{2}{*}{ Entidades Públicas } & Escolas & $26^{*}$ \\
\cline { 2 - 3 } & CFP (IEFP) & 5 \\
\hline \multicolumn{2}{|c|}{ Total } & $\mathbf{4 0}$ \\
\hline
\end{tabular}

Fonte: DREAlentejo, 2010. * Inclui a Escola Superior de Educação de Portalegre. 


\section{O Funcionamento de um Centro Novas Oportunidades}

O Sistema RVCC desenvolve-se através de um processo que é realizado num Centro Novas Oportunidades (actualmente existem 453 Centros Novas Oportunidades).

Os processos de RVCC destinam-se aos adultos que não frequentaram ou concluíram o nível básico $\left(4 .^{\circ}, 6^{\circ}\right.$ ou $9 .^{\circ}$ ano de escolaridade) ou o nível secundário (12..$^{\circ}$ ano de escolaridade) que tenham idade igual ou superior a 18 anos e tenham adquirido conhecimento, saberes e competências através da experiência ao longo da vida.

Para o nível secundário (instituído em 2006), é importante referir que, além da idade ser igual ou superior a 18 anos, é necessário que o indivíduo tenha frequentado o nível secundário, há mais de três anos, sem o concluir (requisito aplicável até 2010) e dispor, no mínimo, de três anos de experiência profissional.

Actualmente, o processo de RVCC tem por base um Referencial de Competências-Chave para a Educação e Formação de Adultos (de Nível Básico ou de Nível Secundário) e organiza-se em duas fases: a do reconhecimento e a da validação das competências (www.anq.gov.pt).

$\mathrm{O}$ adulto que se dirija a um CNO terá de passar pelas fases de acolhimento, diagnóstico/triagem e encaminhamento. Nesta terceira etapa, poderá ser encaminhado para outras ofertas formativas ou para um processo de RVCC, de acordo com o seu perfil e necessidades.

Num processo de RVCC, promove-se a aplicação e desenvolvimento de novas metodologias de reconhecimento e validação de competências, para lá dos espaços educativos formais, cujo objectivo é não só obtenção de um diploma de nível básico ou de nível secundário, mas essencialmente a continuação de processos de educação e formação, numa perspectiva de Aprendizagem ao Longo da Vida e, assim, “contribuir para o desenvolvimento das pessoas e da competitividade das organizações" (in Carta de Qualidade dos Centros RVCC, cit. por Leitão, J. A. in Silva, I. et al, 2002). 


\section{Estudos efectuados no âmbito dos impactos do processo de RVCC}

\section{Estudos sobre os Processos de RVCC em Portugal e no Alentejo}

\section{- Estudos do Centro Interdisciplinar de Estudos Económicos (CIDEC)}

Em Portugal, foram já produzidos estudos sobre os impactos e resultados do processo de Reconhecimento, Validação e Certificação de Competências em Portugal. O Centro Interdisciplinar de Estudos Económicos (CIDEC) realizou, em 2003/2004, um estudo sobre os processos de RVCC analisando os percursos socioprofissionais dos adultos certificados até Dezembro de 2002. Em 2007, volta a publicar novo estudo através de uma investigação empírica baseada na aplicação de um questionário aos adultos certificados em 2003. Este estudo constituiu-se como uma continuação do anterior.

As principais conclusões do $1 .^{\circ}$ estudo (CIDEC, 2004) apontam para os efeitos positivos do processo de RVCC ao nível das "dimensões pessoais do adulto", da “dimensão do emprego e das condições de trabalho" (reforço da empregabilidade") e a “motivação para o prosseguimento de estudos".

O segundo estudo (CIDEC, 2007) aponta para o "reforço da auto-estima e da sua [adulto] auto-valorização" e o contributo que pode dar na "construção de um projecto profissional e de vida" novo. Para os empregados, a razão de participação do adulto é o "desejo de realização profissional e a progressão na carreira" e nos desempregados a expectativa "de reforço da empregabilidade". Refere-se também, neste segundo estudo, que o processo contribui para a "aproximação do adulto ao mercado de trabalho”, "decréscimo de 5,1 pontos percentuais da taxa de desemprego dos adultos certificados", assim como contribuiu para aumentar os níveis de motivação para procurar emprego (caso dos desempregados) e de satisfação dos adultos empregados após a certificação. Apesar destes aspectos, há uma reduzida proporção de adultos que prosseguiram estudos (aproximadamente 10\%), embora manifestem vontade em fazê-lo, numa atitude de valorização e realização de actividades que proporcionem aprendizagens formais ao longo da vida.

O alargamento do sistema de RVCC a novos espaços, especificamente, " $a$ institucionalização do sistema de RVCC no sistema educativo” é apontado como uma oportunidade de diversificar e flexibilizar as práticas, garantindo-se "respostas 
adequadas a diferentes públicos", no entanto, alerta-se para o "risco na possível perda de qualidade pedagógica dessas práticas”, se esse processo não for implementado com alguma atenção na preservação e cumprimento dos princípios que sempre estiveram subjacentes a estes processos (CIDEC, 2007:51-52).

\section{- O estudo sobre o RVCC no Alentejo - os contributos da ESDIME e da}

\section{Fundação Alentejo}

No Alentejo, a ESDIME (Agência para o Desenvolvimento Local no Alentejo Sudoeste, de Ferreira do Alentejo $)^{6}$, entidade que integra a presente investigação, desenvolveu um estudo sobre o impacto do processo nos adultos certificados no processo de RVCC da Casa do S @ber +, desde 2001 a 2004 (ESDIME ，2007:55). A pertinência deste estudo resulta do facto de ter sido entidade pioneira de Cursos EFA e de Centro RVCC. Os objectivos específicos deste estudo consistiram em identificar o perfil dos adultos, avaliar o impacto do processo, identificar as necessidades de formação profissional dos indivíduos após a certificação e conhecer a viabilidade dos processos RVCC. Foram inquiridos 344 indivíduos, num total de 815 adultos certificados. Entre os resultados deste estudo, apontamos os seguintes:

(i) À semelhança de estudos anteriores, no domínio da vida pessoal/social $77,1 \%$ dos adultos inquiridos afirmam que "a passagem pelo RVCC influenciou muito o melhorar a minha auto-estima/dar mais valor a mim mesmo", 72,9\% refere que o processo contribuiu para “aumentar as minhas competências pessoais" e 63,3\% "ser capaz de aprender coisas novas" (ESDIME, 2007: 85-86).

(ii) No domínio profissional, apesar de alguns impactos positivos referidos por $47 \%$ das respostas, cerca de $50 \%$ dos adultos "manifestam a ausência de impactos do RVCC na sua posição profissional elou perderam o emprego no período em referência" (op. cit.:90).

(iii) No domínio académico, mais propriamente, na questão do prosseguimento de estudo, confirmam-se os valores também apontados pelo CIDEC, em que $10,4 \%$ dos adultos certificados (corresponde a 35 adultos) inquiridos

\footnotetext{
${ }^{6}$ Entidade-piloto a testar a metodologia de Curso e Educação e Formação de Adultos em 2000 e uma das primeiras 6 entidades a implementar um Centro de Reconhecimento, Validação e Certificação de Competências, em 2001.
} 
prosseguiram estudos e os restantes "declaram que pretendem vir a fazê-lo num futuro próximo..." (Id.ibid.:73-74).

A seguir à ESDIME, a Fundação Alentejo foi a entidade a constituir-se como Centro de RVCC, em 2001. Em Maio de 2009, apresentou-nos os resultados do impacto do Centro de RVCC que promove desde 2001, na qualificação da população adulta do Alentejo, suportado em dois estudos representativos. Esses estudos incidem sobre a caracterização do perfil dos adultos certificados e o impacte no período pós-certificação, um estudo com objectivos similares àquele que aqui apresentamos. Os dados apresentados situam-se no período de 2002 a 2006. Quanto aos adultos, foram inquiridos adultos certificados no ano de 2005 (total de 251 adultos), a maioria mulheres $(56,6 \%)$.

Os resultados dos estudos, anteriormente referidos, indicam que o processo de RVCC produz impactos mais visíveis a nível pessoal, ao nível do auto-conhecimento e da auto-estima. O mesmo não acontece no campo profissional. Neste domínio, a certificação permitiu aos adultos inquiridos "o reconhecimento consciente da sua (...) utilidade profissional" (Rico \& Libório, 2009:164) e evidenciou que os resultados, em termos de empregabilidade e progressão nas carreiras, ficaram aquém do que seria expectável. A maioria continuou com o mesmo emprego (70,2\%), apenas 11,7\% progrediu na carreira e 9,6\% conseguiu mudar de emprego (Rico \& Libório, 2009:164).

Essa valorização pessoal acentua-se sobretudo no caso das mulheres (estudo da Fundação Alentejo), que se apresentam mais satisfeitas com a realização pessoal que o processo lhes trouxe.

\section{- Os impactos do projecto de investigação "Os impactos do Processo de RVCC, na região Alentejo, no período 2001-2005” (Universidade de Évora, 2010)}

Apresentaremos, de seguida, as principais conclusões sobre os impactos dos processos de RVCC no Alentejo, resultado de uma tese de doutoramento no ramo das Ciências da Educação, na Universidade de Évora. Procurámos caracterizar as alterações dos níveis de qualificação e sobretudo, "estudar" as trajectórias de vida pessoais e profissionais de quem obteve a certificação através de um processo de Reconhecimento, Validação e Certificação de Competências, no período referido. 
Importa referir que do período 2001-2005, foi seleccionado o ano de 2003 para o desenvolvimento da componente empírica da investigação. Este ano permitiu-nos obter um período de 4 anos no pós-certificação, o que era essencial face ao objecto de estudo da investigação.

\section{a. O perfil dos inquiridos}

- Do total de 751 adultos certificados no ano de 2003, 206 responderam ao inquérito por questionário.

- Regista-se, na população respondente, uma predominância do género feminino, pois mais de metade (117 indivíduos) são mulheres. Ao contrário do que acontece em três Centros, no da ESDIME o público certificado é maioritariamente masculino.

- No que respeita às idades dos respondentes, as idades foram agrupadas em sete grupos etários. Tanto no género masculino como no feminino, o grupo etário com maior n..$^{\circ}$ de indivíduos é a que corresponde aos indivíduos com idades entre os 39 e os 45 anos (26,7\% do . $^{\circ}$ total de respondentes).Onde predomina um menor número de indivíduos é no grupo etário situado nos extremos (18-24 e 60 ou mais anos).

- No momento de início do processo de RVCC, no que respeita à situação face ao emprego, 86,9\% dos inquiridos encontra-se empregado (179 adultos) e 12,1\% está na circunstância de desempregado (25). Dos restantes 2 inquiridos, um não respondeu e outro indicou uma outra situação: a de "aposentado". Por cada indivíduo desempregado, à data em que iniciou o processo de RVCC, há mais de 7 empregados.

- No que respeita às habilitações escolares de acesso ao processo e aos grupos etários dos indivíduos, agrupados em 3 grupos (18-38 anos/39-52 anos/Mais de 52 anos), concluímos que os indivíduos com níveis de habilitação de acesso mais elevados (superior ao $6 .^{\circ}$ ano de escolaridade) são mais jovens, enquanto que os níveis de habilitação mais baixos (inferiores ao $6^{\circ}$ ano) estão identificados com os indivíduos que se situam nos grupos etários mais elevados. 
- Quanto ao nível de certificação obtido, aproximadamente 89\% dos adultos certificaram o nível B3 (9. ${ }^{\circ}$ ano) e $9 \%$ o nível B2 (6. ${ }^{\circ}$ ano), sendo residual o . $^{\circ}$ de certificações no nível $\mathrm{B} 1 ; 1 \%$ dos adultos inquiridos não respondeu a esta questão.

\section{b. Avaliação dos Impactos do Processo de RVCC nos adultos certificados}

Neste ponto, iremos procurar apresentar a avaliação que os adultos fizeram do impacto do processo de RVCC nas suas vidas, nas diversas dimensões que a caracterizam. No inquérito, procurámos averiguar possíveis incongruências nessa avaliação feita pelos adultos. Dessa forma, apresentámos uma segunda questão (Questão n. ${ }^{\circ}$ 20), inquirindo os indivíduos acerca da avaliação do processo de RVCC, nas diversas dimensões, de forma generalizada, procurando identificar possíveis desfasamentos na avaliação do processo de RVCC.

Daremos particular atenção ao aspecto do prosseguimento de estudos, na medida em que constitui uma variável importante no âmbito dos objectivos do estudo.

\section{b.1.- Importância atribuída ao processo de RVCC}

Com base no inquérito por questionário aplicado, foi possível identificar os rácios “importante/sem importância” em cada um dos itens. Quanto maior o valor deste rácio, maior a importância dada ao processo de RVCC pelos respondentes.

- Verificamos pela análise dos rácios que a "valorização das minhas competências e conhecimentos pessoais" adquiridos (item n. ${ }^{\circ} 1$ ) e a "melhoria do conhecimento das minhas capacidades” são, efectivamente, os aspectos mais valorizados (item $n .^{\circ} 2$ ).

- Por outro lado, a "melhoria da minha situação no emprego" (item n. ${ }^{\circ}$ 8) e a “valorização social pela comunidade onde estou integrado" (item n. ${ }^{\circ}$ ) são os menos valorizados pelos inquiridos.

- Outra conclusão a que chegamos é que os três itens mais valorizados são correspondentes a dimensões associadas a aspectos de natureza intrínseca, 
de valorização e de reconhecimento pessoal das suas competências e um aumento de auto-confiança em si.

- Os itens menos valorizados pelos respondentes dizem respeito à dimensão profissional (nomeadamente a possibilidade de melhoria de emprego) e de reconhecimento social, quer pela família, quer pela comunidade, do que se conclui que o impacto do processo nessas duas dimensões foi pouco valorizado pelos inquiridos no estudo.

- Se é verdade que uma das dificuldades apontadas pelos adultos no decorrer do processo foi a adaptação a uma nova rotina, também se verifica que esse aspecto foi avaliado satisfatoriamente pelos inquiridos, do que se pode inferir que o processo de RVCC poderá ter ajudado os indivíduos a responder às novas circunstâncias (item n. ${ }^{\circ}$ 7).

Apresentamos, de seguida, a importância que os adultos atribuíram ao processo de RVCC, ao nível das consequências do mesmo em várias dimensões, optámos por apresentar a questão, também recorrendo a uma Escala tipo Likert.

Assim, foram apresentadas cinco dimensões (profissional, académica, pessoal, familiar e comunitária), cuja avaliação dos adultos foi a seguinte:

- a Dimensão Pessoal é a que os respondentes mais valorizaram, reconhecendo-se uma maior importância do impacto que o processo induziu nessa área.

- as Dimensões Familiar e Profissional são as menos valorizadas, o que vem reforçar os resultados da avaliação apresentada anteriormente.

\section{b.2. O prosseguimento de estudos}

- Dos 206 respondentes ao inquérito, apenas $15 \%$ prosseguiu estudos após o processo de RVCC. Por cada indivíduo que prosseguiu os estudos, mais de 5 não o fizeram, como podemos observar a partir da leitura do quadro seguinte. 
Quadro 3. Número de adultos que prosseguiu estudos

\begin{tabular}{|c|c|c|c|}
\hline \multicolumn{2}{|c|}{} & Frequência Absoluta (n. $\left.{ }^{\circ}\right)$ & Frequência Relativa (\%) \\
\hline \multirow{2}{*}{} & Não & 175 & 85,0 \\
\cline { 2 - 4 } & Sim & $\mathbf{3 1}$ & $\mathbf{1 5 , 0}$ \\
\cline { 2 - 4 } & Total & $\mathbf{2 0 6}$ & $\mathbf{1 0 0 , 0}$ \\
\hline \multicolumn{2}{|r}{} \\
\hline
\end{tabular}

- Dos 31 adultos que prosseguiram estudos (15\%), 3 concluíram o ensino secundário, e apenas 2 optaram por vias formativas para adultos, como os Cursos de Educação e Formação de Adultos (EFA). Apenas 1 adulto (3,2\%) prosseguiu estudos de nível superior. Destes 31 indivíduos, há uma predominância de mulheres que após o processo de RVCC prosseguiram os estudos (19).

- Para os adultos que não tinham prosseguido estudos, procurámos saber se, efectivamente, pensavam vir a fazê-lo, no futuro. Verificamos que, num total de 175 respostas válidas, 134 adultos referiram que pretendiam prosseguir a sua aprendizagem em ambientes formais e certificados $(76,6 \%)$ :

Quadro 4. Intenção de prosseguimento dos estudos

\begin{tabular}{|c|c|c|c|}
\hline \multicolumn{2}{|c|}{} & $\begin{array}{c}\text { Frequência Absoluta } \\
\left(\mathbf{n} .^{\mathbf{0}}\right)\end{array}$ & $\begin{array}{c}\text { Frequência Relativa } \\
(\mathbf{\%})\end{array}$ \\
\hline \multirow{3}{*}{} & Sim & $\mathbf{1 3 4}$ & $\mathbf{7 6 , 6}$ \\
\cline { 2 - 4 } & Não & 41 & 23,4 \\
\cline { 2 - 4 } & Total & $\mathbf{1 7 5}$ & $\mathbf{1 0 0 , 0}$ \\
\hline
\end{tabular}

Fonte: Inquérito por Questionário (2007).

- Os indivíduos do género feminino valorizaram mais o prosseguimento de estudos pois, dos 134 adultos, 79 são mulheres $(58,9 \%)$ e só 55 são homens, tal como se verificou anteriormente.

- Verificou-se a existência de um número, pouco significativo, de adultos que pretendia prosseguir estudos de nível secundário através da frequência de ofertas formativas e não apenas por um percurso de RVCC. São evidências desta conclusão, a fraca manifestação de interesse pelos Cursos Profissionais e Cursos EFA com apenas 5 escolhas. 
- Pareceu-nos existir a ideia pré-estabelecida e adquirida pelos adultos de que, para continuar a estudar, o melhor caminho é o RVCC, o que não corresponde necessariamente à realidade. Um percurso de RVCC implica um acumular de experiência e de aprendizagem ao longo da vida, que só será possível de concretizar pela frequência de outras ofertas formativas e experiências tidas em contextos não formais e informais de aprendizagem.

\section{Apresentação do projecto de investigação “As Novas Núpcias da Qualificação no} Alentejo"

Actualmente, encontra-se em curso, o desenvolvimento de um projecto de investigação, na Universidade de Évora. Este projecto pretende estudar os impactos do reconhecimento e validação dos adquiridos experienciais, na região Alentejo, no período 2001-2005, e qual a sua relação com o princípio da Aprendizagem ao Longo da Vida (ALV).

Este projecto é financiado pela Fundação para a Ciência e Tecnologia (FCT) e decorrerá entre Junho de 2010 e Dezembro de 2012.

\section{Questões de Partida}

Como questões de partida definimos duas:

O princípio da Aprendizagem ao Longo da Vida (que esteve na génese do próprio sistema de RVCC) é uma realidade concretizada pela população em estudo?

$\square$ Em caso afirmativo, o mesmo encontra alguma consequência nos planos individual, profissional e social?

\section{Natureza do estudo e metodologia a utilizar}

É um estudo de natureza qualitativa que pretende estudar as trajectórias de vida dos indivíduos após a oportunidade de qualificação concretizada entre 2001 e 2005 . Ao nível das metodologias e instrumentos a utilizar privilegiaremos o recurso ao inquérito 
por questionário (Sousa, 2005). As técnicas de análise mais importantes serão a análise estatística (descritiva e inferencial) e, também, a análise de conteúdo (Bardin, 1997), atendendo a que se pretende construir um instrumento que contemple questões fechadas e questões de natureza aberta.

\section{Universo considerado}

No estudo será considerado um universo constituído por 2969 indivíduos certificados pelos seis Centros de RVCC, em funcionamento na região Alentejo, no período compreendido entre 2001-2005.

\section{Concluindo...}

Esperamos poder retratar, em comunicações futuras, alguns dos impactos dos processos de RVCC no Alentejo, naquele período, procurando caracterizar as alterações dos níveis de qualificação e sobretudo, "estudar" as trajectórias de vida pessoais e profissionais de quem obteve a certificação através de um processo de Reconhecimento, Validação e Certificação de Competências e a relação desses impactos com o princípio da Aprendizagem ao Longo da Vida $(\mathrm{ALV})$.

\section{Bibliografia}

ALCOFORADO, L. (2001). "O Modelo da Competência e os adultos portugueses não qualificados". In Revista Portuguesa de Pedagogia. Ano 35. N. ${ }^{\circ}$ 1. Coimbra: Faculdade de Psicologia e de Ciências da Educação. pp.67-83.

ALONSO, L. (2000). "A construção de um referencial de competência-chave para a cidadania e empregabilidade”. In Revista Saber Mais. N. ${ }^{\circ}$ 5. Lisboa: ANEFA. pp.20-27.

ALONSO, L., IMAGINÁRIO L. et al (2001). Referencial de Competências-Chave - Educação e Formação de Adultos. Lisboa: ANEFA. 
ALVES, M., ESTÊVÃO, C. et al (2006).’Desenvolver e avaliar competências na escola: metanarrativas de legitimação em confronto. In Gérard Figari et al (orgs.). Avaliação de Competências e Aprendizagens Experienciais. Saberes, modelos e métodos. Lisboa: Educa. pp.255-275.

AMORIM, J. (2006). O Impacto da Educação e Formação de Adultos no Desenvolvimento Vocacional e da Cidadania - A Metamorfose das Borboletas. Colecção Cadernos de Emprego e Relações de Trabalho n. ${ }^{\text {5. 1. }}$ Edição. Lisboa: Ministério do Trabalho e Segurança Social - Direcção-Geral do Emprego e das Relações de Trabalho.

ARÉNILLA, L., GOSSOT, B. et al (2001). Dicionário de Pedagogia. Lisboa: Instituto Piaget.

ÁVILA, P. (2008). A Literacia dos Adultos. Competências-Chave na Sociedade do Conhecimento. Lisboa: Celta Editora.

CANÁRIO, R. (1999). Educação de Adultos. Um Campo e uma Problemática. Lisboa: Educa.

CARNEIRO, R. (2001a). "Entrevista a Roberto Carneiro - É preciso criar nas pessoas a pulsão de aprender”. In Revista Saber Mais. N. ${ }^{\circ}$ 9.Lisboa: ANEFA. pp.18-23.

CAVACO, C. (2002). Aprender fora da escola. Lisboa: Educa.

CIDEC (2004). O Impacto do Reconhecimento e Certificação de Competências Adquiridas ao Longo da Vida. Lisboa: ME/DGFV.

CIDEC (2007). O Impacto do Reconhecimento e Certificação de Competências Adquiridas ao Longo da Vida: Actualização e Aperfeiçoamento. Lisboa: ME/DGFV.

COMISSÃO EUROPEIA (2000). Memorando sobre Aprendizagem ao Longo da Vida. Bruxelas.

CORREIA , A. \& CABETE, D. (2002). "O valor do que aprendemos ao longo da nossa vida... e a importância do Sistema Português de Reconhecimento, Validação e Certificação de Competências". In Isabel Silva et al (Orgs.). Educação e Formação de Adultos: Factor de Desenvolvimento Inovação e Competitividade. Lisboa: ANEFA, 45-53.

CORREIA, A. (2006). "O Sistema Nacional de Reconhecimento, Validação e Certificação de Competências". In Albano Estrela et al (orgs.). Actas do XVII Colóquio ADMEE-Europa. Lisboa: FPCEUL. pp.267-274. 
COSTA, A. (2002a). "Um processo de desenvolvimento social de competências e certificações". In Isabel Silva et al (orgs). Educação e Formação de Adultos. Factor de Desenvolvimento, Inovação e Competitividade. Lisboa: ANEFA. pp.7-11.

COSTA, A. (2002a). "Um processo de desenvolvimento social de competências e certificações". In Isabel Silva et al (orgs). Educação e Formação de Adultos. Factor de Desenvolvimento, Inovação e Competitividade. Lisboa: ANEFA. pp.7-11.

DGFV (2004). Reconhecimento e Validação de Competências. Instrumentos de mediação. Lisboa: Ministério da Educação.

ESDIME (2007). Estudo sobre o Impacto da Certificação de Competências na Vida das Pessoas: A Experiência da Esdime. Camarate: IEFP.

FIDALGO, N. \& FIDALGO, F. (2007). "Reflexos sociais da lógica de competências: o processo de individualização em foco". In Fernando Fidalgo et al (orgs.). Educação Profissional e a Lógica das Competências. Petrópolis: Editora Vozes. pp.17-70.

GOMES, M. (2006). "Referencial de Competências-Chave para a Educação e Formação de Adultos Nível Secundário". In Maria Gomes (Coord). Referencial de Competências-Chave para a Educação e Formação de Adultos - Nível Secundário. Lisboa: ME/DGFV.pp.9-29

GOMES, M. (Coords.) (2006). Referencial de Competências-Chave para a Educação e Formação de Adultos - Nível Secundário. Lisboa: DGFV.

GOMES, M. et al (2006). Referencial de Competências-Chave para a Educação e Formação de AdultosNível Secundário. Lisboa: ME/DGFV.

GONÇALVES, M. \& FERNANDES, M. (Coords.) (2007). MAPA - Motivar os Adultos para a Aprendizagem. Os percursos do projecto.1. ${ }^{a}$ Edição. Lisboa: Agência Nacional para a Qualificação, I.P.

HOWARD, U. (2001). [Texto sem título integrado em "Um Entre Seis: O Grupo de Trabalho B"]. In ANEFA. Conferência Europeia Educação e Formação de Adultos na Europa. As Competências-Chave para a Cidadania e a Empregabilidade. Lisboa: ANEFA. pp. 97-101.

IMAGINÁRIO, L. (2007). “(Re)valorizar a aprendizagem: práticas e respostas europeias à validação de aprendizagens não formais e informais". In Conferência Valorizar a Aprendizagem: práticas europeias de validação de aprendizagens não formais e informais”. Lisboa. Texto policopiado (distribuído). pp.117. 
IMAGINÁRIO, L. et al (2002). A Aprendizagem dos Adultos em Portugal: exame temático no âmbito da OCDE. Lisboa: ANEFA.

INE (2002). Censos 2001. Resultados Definitivos. Lisboa: INE.

LAGES, M. (2006). "Da avaliação controlo à avaliação processo: as histórias de vida e/ou a razão narrativa.”. In Albano Estrela et al (orgs.). Actas do XVII Colóquio ADMEE-Europa. Lisboa: FPCE-UL. pp. 468-479.

LE BOTERF, G. (1994). De la Competénce - Essai sur un Attracteur Étrange. Paris: Les Éditions d’Organisation.

MINISTÉRIO DA EDUCAÇÃO (1998). Processos de Reconhecimento e Validação de Competências. Colecção Educação/Formação n. ${ }^{\circ}$ 5. Lisboa: Ministério da Educação. Departamento da Educação Básica.

NICO, B., NICO, L. et al (2008a). "Reconhecimento, Validação e Certificação de Competências no Alentejo: uma visão da realidade". In Bravo Nico (orgs.). Aprender no Alentejo IV Encontro Regional de Educação. Évora: Departamento de Pedagogia e Educação da Universidade de Évora. pp.211-217.

NOGUEIRA, A. (1996). Para uma Educação Permanente à Roda da Vida. Coimbra: Instituto de Inovação Educacional.

NORBECK, J. (1997). "O educando adulto”. In Lys Samartino \& Maria Torres (orgs.). Educação de Adultos. Colecção Cadernos de Formação. N. ${ }^{\circ}$ 3. Lisboa: Ministério da Educação/Departamento da Educação Básica. Núcleo da Educação Recorrente e Extra-Escolar. pp.30-49.

PERRENOUD, P. (2000). “Construindo Competências”. In Nova Escola. Entrevista de Paola.

PINTO, M. (2006). “Avaliação de Competências/Resolução de Problemas em Contexto escolar”. In Gérard Figari et al (orgs.). Avaliação de Competências e Aprendizagens Experienciais. Saberes, modelos e métodos. Lisboa: Educa. pp.335-347.

PIRES, A. (2005). Educação e Formação ao Longo da Vida: análise crítica dos sistemas e dispositivos de reconhecimento e validação de aprendizagens e competências. Lisboa: Fundação Calouste Gulbenkian e Fundação para a Ciência e Tecnologia.

PIRES, A. (2006). "O Reconhecimento e Validação das Aprendizagens Adquiridas pela Experiência e a Investigação". In Gérard Figari et al (orgs.). Avaliação de Competências e Aprendizagens Experienciais. Saberes, modelos e métodos. Lisboa: Educa. pp.437-450. 
QUINTAS, H. (2008). Educação de Adultos: vida no currículo e currículo na vida. Lisboa: Agência Nacional para a Qualificação, I.P.

RENS, J. (2001). [Texto sem título integrado na Segunda Sessão Plenária]. In ANEFA. Conferência Europeia Educação e Formação de Adultos na Europa. As Competências-Chave para a Cidadania e a Empregabilidade. Lisboa: ANEFA. pp.51-53.

RICO, H. \& LIBÓRIO, T. (2009). Impacte do Centro de RVCC da Fundação Alentejo na qualificação dos alentejanos. Évora: Fundação Alentejo.

RICO, H. (2007). O Impacto do Processo de RVCC: perspectivas dos adultos certificados. [Dissertação apresentada à Universidade de Coimbra, tendo em vista a obtenção do grau de Mestre em Ciências da Educação]. Coimbra: Faculdade de Psicologia e de Ciências da Educação da Universidade de Coimbra.

RODRIGUES, P. \& PERALTA, H. (2006). "Programas Comunitários de Intercâmbio Universitário: aprendizagens e desenvolvimento de competências. Estudo Exploratório na Universidade de Lisboa. In Gérard Figari et al (orgs.). Avaliação de Competências e Aprendizagens Experienciais. Saberes, modelos e métodos. Lisboa: Educa. pp.229-254.

ROLDÃO, M. (2003). Gestão do Currículo e Avaliação de Competências - As questões dos professores. 1. ${ }^{a}$ Edição. Lisboa: Editorial Presença.

SANTOS, N. \& FIDALGO, F. (2007). “Os (des)caminhos da certificação de competências no Brasil”. In Fernando Fidalgo et al (orgs.). Educação Profissional e a Lógica das Competências. Petrópolis: Editora Vozes. pp.71-110.

SILVA, I. et al (Orgs.) (2002). Educação e Formação de Adultos: Factor de Desenvolvimento Inovação e Competitividade. Lisboa: ANEFA.

SILVA, I., LEITÃO, J., TRIGO, M. (Orgs.). (2002). Educação e Formação de Adultos: Factor de Desenvolvimento Inovação e Competitividade. Lisboa: ANEFA. 